been able to make substantial scientific contributions to Occasional Papers which are published by the Museum.

\section{Forest Tree Seed Directory}

The 1961 Forest Tree Seed Directory was produced by the Food and Agriculture Organization of the United Nations as a special edition for the Seed Year Campaign (Pp. i $+470+\mathrm{iii}+49$. Rome: Food and Agriculture Organization of the United Nations; London: H.M.S.O., 1961. 10s.; 2 dollars). It is a most comprehensive and detailed document. The species are arranged in alphabetical order of botanical names, and data are given under the following heads: country; seed supplier's number (listed separately), longitude, latitude and altitude; month or months for seed order; if certificate required; if small quantities can be obtained free, at cost of collection and postage, on exchange on trial basis for research work, and so on; and finally, the locality. This section forms by far the bulk of the publication and it provides an immense amount of information. Three thoughtful appendixes add to the value of the work. The first is a note on eucalypt seed because of the widespread interest in the genus. The list of 118 species is grouped by climatic zones, and further details are provided by way of rain types and availability of seed. The second appendix contains examples of certificates of seed quality and origin. The final appendix sets out the present international rules for forest tree seed testing. The contributors and compilers are to be congratulated on providing such a useful reference work.

\section{Recent Forestry Commission Publications}

THREE Forestry Commission Leaflets have recently been published (No. 16: Larch Canker and Dieback. Pp. 5. 9d. net. No. 31: The Grey Squirrel: a Woodland Pest. Pp. 18. 1s. 6d. net. No. 46: Titmice in Woodlands. By C. E. Palmar. Pp. 20. 1s. 9d. net. London: H.M.S.O., 1962). The first deals with lareh canker and dieback and is a revision of a previous leaflet (1927, reprinted 1939). The disease (Trichoscyphella willkommii) is described and preventive measures considered. The leaflet is very well illustrated. The second leaflet, dealing with the grey squirrel, is an account of this small animal's spread in Britain, its life history and habits and the damage it causes. Suggested control measures are given. Although its main economic damage is the stripping of bark of growing trees, the grey squirrel feeds on tree seeds, and it can be a pest of orchard and garden, occasionally of farm crops, and it can destroy game birds' eggs. In dealing with titmice in Leaflet No. 46, the author concludes, "It will be seen that the tits are fascinating forest birds which are more likely than not of benefit to the forester". One wonders if this well-written and well-illustrated descriptive account of six species of tit should not have more appropriately come from the Nature Conservancy ?

Chalk Downland Afforestation (Forestry Commission Bulletin No. 34. By R. F. Wood and M. Nimmo. Pp. iii $+45+24$ plates. London: H.M.S.O., 10s. net) is a timely publication. In England, chalk is found in parts of the east, south-east and south, but it is not a formation of the first importance to the forester. However, there has always been a considerable area of woodland on the challk. Afforestation on chalk downland has been fraught with many difficulties such as nutritional disorders and poor water-storage capacity of the rock and, in addition, blasting by salt winds due to the proximity of many of the areas to the coast. The Bulletin describes the chalk downland habitat and it gives a history of afforestation works and an up-to-date account of the knowledge gleaned. from the Forestry Commission's experimental works begun in 1927. The notes given on various species will be of great practical value. This very readable booklet brings together a great deal of useful information and it is profusely illustrated.

\section{Cytogenetics}

YET another addition to the ever-increasing array of journals has just been published. Cytogenetics is devoted solely to the expanding field of cytogenetics (1, No. 1; 1962. Edited by Dr. H. P. Klinger. Pp. 64. Published six times a year. Basle and New York: S. Karger, 1962. Annual subseription-rate: 95 Swiss francs; 22.80 dollars). According to the publishers, this journal "is designed to provide investigators in the field of animal cytogenetics with a medium in which to publish original findings. Emphasis will be placed on vertebrate and mammalian cytogenetics, with special reference to man. Papers on related subjects will be considered by the editors in the light of their relevance to the general policy of the journal". The contents of the first number include one paper on "Human Oögenesis" and five papers describing human genetical defects and their corresponding chromosomal patterns. It seems a pity to restrict the journal to papers of this type, for which there are numerous other publications, and not to include papers from the lesser known fields of invertebrate cytogenetics. A brief book review is included, mainly books of a general cytological nature. The journal is published by S. Karger (Basle and New York) and the editorial office, under the direction of Dr. H. P. Klinger, is located in the Department of Anatomy, University of Basle.

\section{Soils and Fertilizers}

The Bureau of Soils, one of the Commonwealth Agricultural Bureaux, was established at Rothamsted Experimental Station and has been of the greatest assistance to workers in the field of soil science, particularly in providing references and summaries of literature for those lacking full library facilities. The Bureau prepares Soils and Fertilizers, which is mainly a comprehensive set of abstracts from world literature, under a decimal system of classification for entries according to the five main classes-soils, crop production, agricultural crops, tree crops and horticultural crops. There is also an index of authors, a summary of reports from research stations and an annotated list of bibliographies which are available to applicants. In addition, each issue usually carries one or more short reviews of important topics or of recently published books. For example, the present number $(25$, No. $3 ; 1962)$ has reviews on Plant-root Exudates in Relation to the Rhizosphere Microflora, by A. D. Rovira, and on the books Soil Organic Matter, by M. M. Kononova, and Muddy Sediments, by P. G. H. Boswell. The Bureau has also issued, since 1931, a series of volumes on the bibliography of soil science, fertilizers and general agronomy, the ninth, covering the period $1956-59$ and published in 1960 , being complete with index to classification numbers, a list of abbreviations, an author index and a subject index. These services are of incalculable value to all engaged in soil science and related interests. Copies are available from the Commonwealth Agricultural Bureaux, Farnham Royal, Bucks. 